\title{
AN ACID CITRATE-DEXTROSE SOLUTION WITH LOW WATER VOLUME AND LOW DEXTROSE CONCENTRATION ${ }^{1}$
}

\author{
By MAX M. STRUMIA, ALTON D. BLAKE, JR., AND JOHN J. MCGRAW, JR. \\ WITH THE TECHNICAL ASSISTANCE OF MISS MARGARET DOLAN AND \\ MISS LOUISE COLWELL \\ (From the Laboratory of Clinical Pathology of the Bryn Mawr Hospital, \\ Bryn Mazer, Pennsylvania)
}

(Received for publication August 31, 1946)

The blood preservative introduced by Loutit and Mollison (1) consisting essentially of a sodium citrate-dextrose mixture of relatively low $\mathrm{pH}$, has proved superior to previously employed preserving fluids. The original formula and many subsequent modifications have a rather high volume. This produces considerable dilution of the plasma proteins.

The purpose of this study, begun in June 1944, was to obtain an A.C.D. solution of lower volume, so as to maintain an optimal concentration of plasma proteins, maintain or improve the capacity to preserve erythrocytes, and at the same time insure maximal stability of the resulting plasma.

The first solution tested was one proposed by Rapoport, as follows :

$\begin{array}{ll}\text { Sodium citrate (trisodium dihydric) } & 1.66 \text { grams } \\ \text { Citric acid (monohydric) } & 0.59 \text { gram } \\ \text { Distilled water } & 100 \mathrm{ml} .\end{array}$

$22.5 \mathrm{ml}$. of 15 per cent dextrose were added to $90 \mathrm{ml}$. of this solution, and the resulting solution was sterilized by autoclaving for 20 minutes at $120^{\circ} \mathrm{C}$. This formula can be written as follows for the sake of comparison with other formulas:

\section{A.C.D. Rapoport}

Sodium citrate (trisodium dihydric)

Citric acid (monohydric)

Dextrose

Water

1.50 grams

.55 gram

3.37 grams

$112.5 \mathrm{ml}$.

$112.5 \mathrm{ml}$. of this solution were used for each $500 \mathrm{ml}$. of blood collected. The solution was cooled to $4^{\circ} \mathrm{C}$. previous to use.

1 This paper is the 21st of a series on blood, plasma, and plasma substitutes from the Laboratory of Clinical Pathology of the Bryn Mawr Hospital. The work described in this paper was done under a contract recommended by the Committee on Medical Research between the Office of Scientific Research and Development' and the Bryn Mawr Hospital, and with the aid of the Bryn Mawr Research Foundation.
The post-transfusion survival of erythrocytes collected in this solution was tested with the radioactive iron technic (2). With fresh blood there was an immediate loss of 6 to 10 percent of the transfused cells. There was no increased loss of transfused cells after 10 days of preservation at $4^{\circ} \mathrm{C}$. After 21 days of storage the survival dropped to 40 to 58 per cent and at the end of 31 days of storage the preservation was less than 20 per cent.

In a first modification of Rapoport's solution the amounts of citrate and glucose were slightly increased and the amount of water reduced. The formula was as follows:

$$
\text { Bryn Mawr A.C.D. No. } 2
$$

$\begin{array}{ll}\text { Sodium citrate (trisodium, dihydric) } & 1.6 \text { grams } \\ \text { Citric acid (monohydric) } & 0.56 \text { gram } \\ \text { Dextrose (anhydrous) } & 3.6 \text { grams } \\ \text { Water to } 100 \mathrm{ml} . & \end{array}$

One hundred $\mathrm{ml}$. of this solution were used for each $500 \mathrm{ml}$. of blood.

This solution was adopted for routine use in the hospital and by January 16, 1945, a total of 587 lots of blood had been collected in this solution. The results of 139 whole blood transfusions were thoroughly studied. It was concluded from these preliminary studies that this solution was no better than the previous one for preservation of erythrocytes, but it was found that the plasma obtained was somewhat more stable. The studies of the plasma composition will be reported later on. In vitro studies showed that the concentration of dextrose was much higher than the optimal. This conclusion was reached from studies of the osmotic resistance, mean corpuscular volume, and hemoglobin concentration in the supernatant plasma. Since this solution was not completely satisfactory, it was decided to study the effect of varying amounts of dextrose. At the 
same time the volume was reduced to $75 \mathrm{ml}$. Similar results were reported by Rapoport (3).

A basic formula was then adopted:

$\begin{array}{ll}\text { Sodium citrate (trisodium, dihydric) } & 1.6 \text { grams } \\ \text { Citric acid (monohydric) } & 0.56 \text { gram } \\ \text { Water } & 75 \mathrm{ml} .\end{array}$

Varying amounts of dextrose were added to this basic formula as follows: 1.6, 1.8, 2.0, 2.2, 2.4 grams. Seventy-five $\mathrm{ml}$. of the resulting solutions, chilled, were used for $500 \mathrm{ml}$. of blood.

\section{IN VITRO STUDIES OF A.C.D. SOLUTIONS WITH VARY- ING AMOUNTS OF DEXTROSE}

These included mean corpuscular volume, hemoglobin concentration in the supernatant plasma, and osmotic resistance. Samples of blood were prepared for in vitro studies as follows: $500 \mathrm{ml}$. of blood were obtained in a chilled donor bottle containing 1.6 grams of sodium citrate and .56 gram of citric acid in $50 \mathrm{ml}$. of water. Immediately after collection, the blood was divided into 5 equal aliquots and immediately transferred to 5 bottles, chilled, each containing $5 \mathrm{ml}$. of a solution of dextrose to yield the final concentration noted previously. A determination of the hemoglobin concentartion in the $\mathbf{5}$ samples was done to correct any inequality in the measuring of the samples. All figures given have been corrected. Samples of blood were taken from each solution to be tested immediately after mixing. The blood was then stored at $4^{\circ} \mathrm{C}$. and similar samples were taken at the end of 7,14 , 21 , and 28 days. Before sampling, the blood was thoroughly mixed by gentle rotation for a period of 5 minutes. At the completion of this time approximately 7 to $8 \mathrm{ml}$. of blood were removed aseptically and used for the various tests.

The technic used for the determination of the mean corpuscular volume is as follows: One ml. of blood was placed in a Wintrobe hematocrit tube and this was centrifuged at 3,600 r.p.m. for 30 minutes. The hematocrit was then read and the blood was again centrifuged at 3,600 r.p.m. for 10 minutes. If there was no change in the readings, the hematocrit was then read directly and an erythrocyte count was done on the same sample. The mean corpuscular volume was calculated in the usual manner.

The technic for the determination of the hemoglobin in the supernatant plasma is as follows: a 5 -ml. sample of blood was centrifuged for 10 minutes at 1,800 r.p.m. At the end of this time the plasma was removed by the use of a capillary pipette and the hemoglobin determined as described elsewhere (4).

The technic used for determining the osmotic resistance is that suggested by Parpart (5), modified as follows : .05 $\mathrm{ml}$. of whole blood was added to $5 \mathrm{ml}$. of the various solutions of Series I. ${ }^{2}$ These mixtures were then placed in

${ }^{2}$ Series I and Series II each consist of 10 tubes, each containing $5 \mathrm{ml}$. of a sodium chloride solution of the following concentration per cent: the water bath at $37^{\circ} \mathrm{C}$. for $1 / 2$ hour. At the end of this time the tubes were removed from the water bath and 5 $\mathrm{ml}$. of each of the corresponding solutions of series II were added, the tubes were thoroughly mixed, centrifuged for 10 minutes at 3,600 r.p.m. The hemoglobin in the supernatant fluid was then estimated with the Klett photoelectric colorimeter. The hemoglobin content of the tube containing 0.1 per cent sodium chloride was considered as 100 per cent hemolyzed; the hemoglobin reading of the other tubes was recorded in per cent of this value. In Figure 2 sodium chloride concentration giving 50 per cent hemolysis are plotted against time of storage for the various preservative solutions.

\section{Mean corpuscular volume}

For the $\mathbf{5}$ solutions tested, those with the higher dextrose concentration showed an increasing fluctuation in the values of the mean corpuscular volume. The 2 highest concentrations of dextrose produced an abnormally high mean corpuscular volume of the stored cells. The pattern of variations for each concentration has been found to be fairly constant for blood from the same source (see Figure 1).

\section{Osmotic resistance}

For the first 3 weeks of preservation there was little difference between the cells preserved in the various concentrations of dextrose. A slight spread of values occurred after the twenty-first day of storage, the lower concentrations of glucose showing a better osmotic resistance than the higher (see Figure 2).

\section{Hemoglobin concentration in supernatant plasma}

There appears to be no difference up to the fourteenth day of storage between erythrocytes in the various concentrations of dextrose. A definite spread of values occurred at the end of the third

\begin{tabular}{ccc}
\multicolumn{3}{c}{$\begin{array}{c}\text { Sodium chloride } \\
\text { grams per cent }\end{array}$} \\
Tube No. & Series I & Series II \\
1 & 0.100 & 1.900 \\
2 & 0.300 & 1.700 \\
3 & 0.400 & 1.600 \\
4 & 0.450 & 1.550 \\
5 & 0.500 & 1.500 \\
6 & 0.550 & 1.450 \\
7 & 0.600 & 1.400 \\
8 & 0.700 & 1.300 \\
9 & 0.900 & 1.100 \\
10 & 1.000 & 1.000 \\
Intermediate concentrations are used whenever necessary.
\end{tabular}

Intermediate concentrations are used whenéver necessary. 


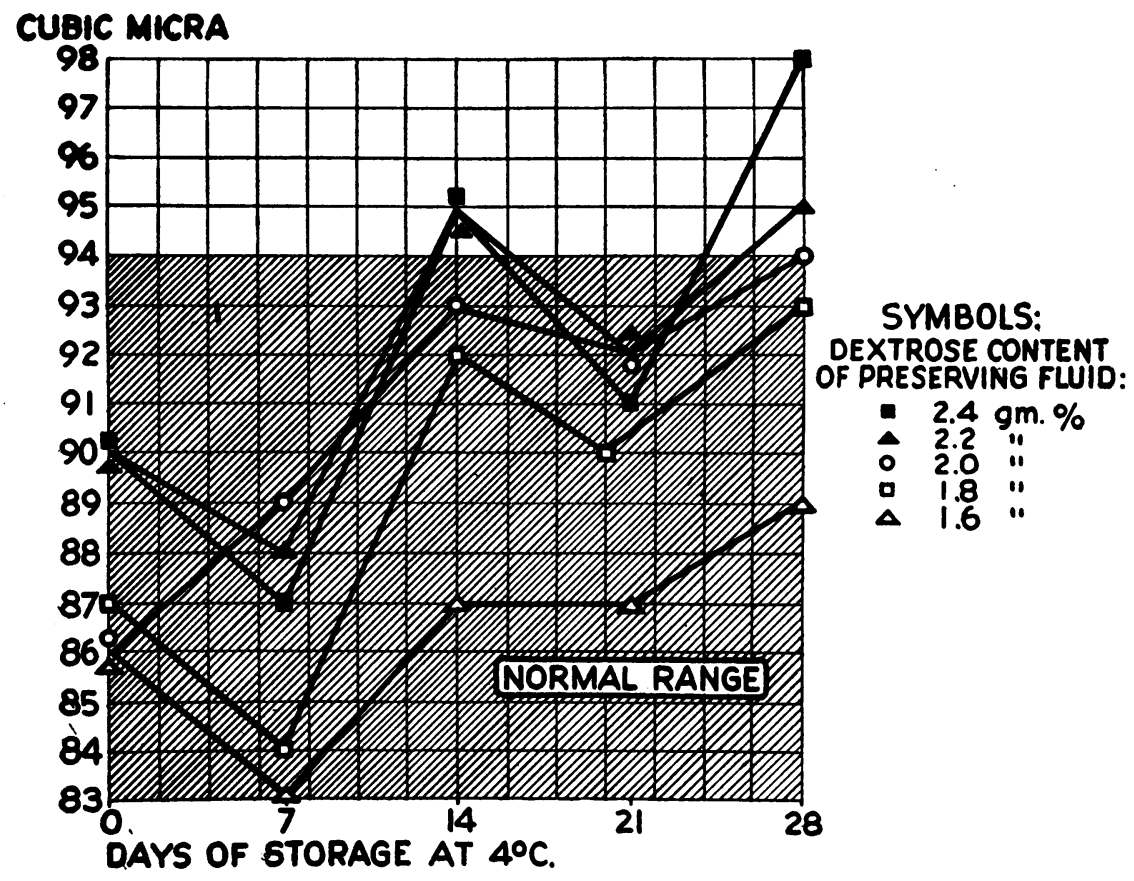

Fig. 1. Effect of Dextrose Concentration on the Mean Corpuscular Volume

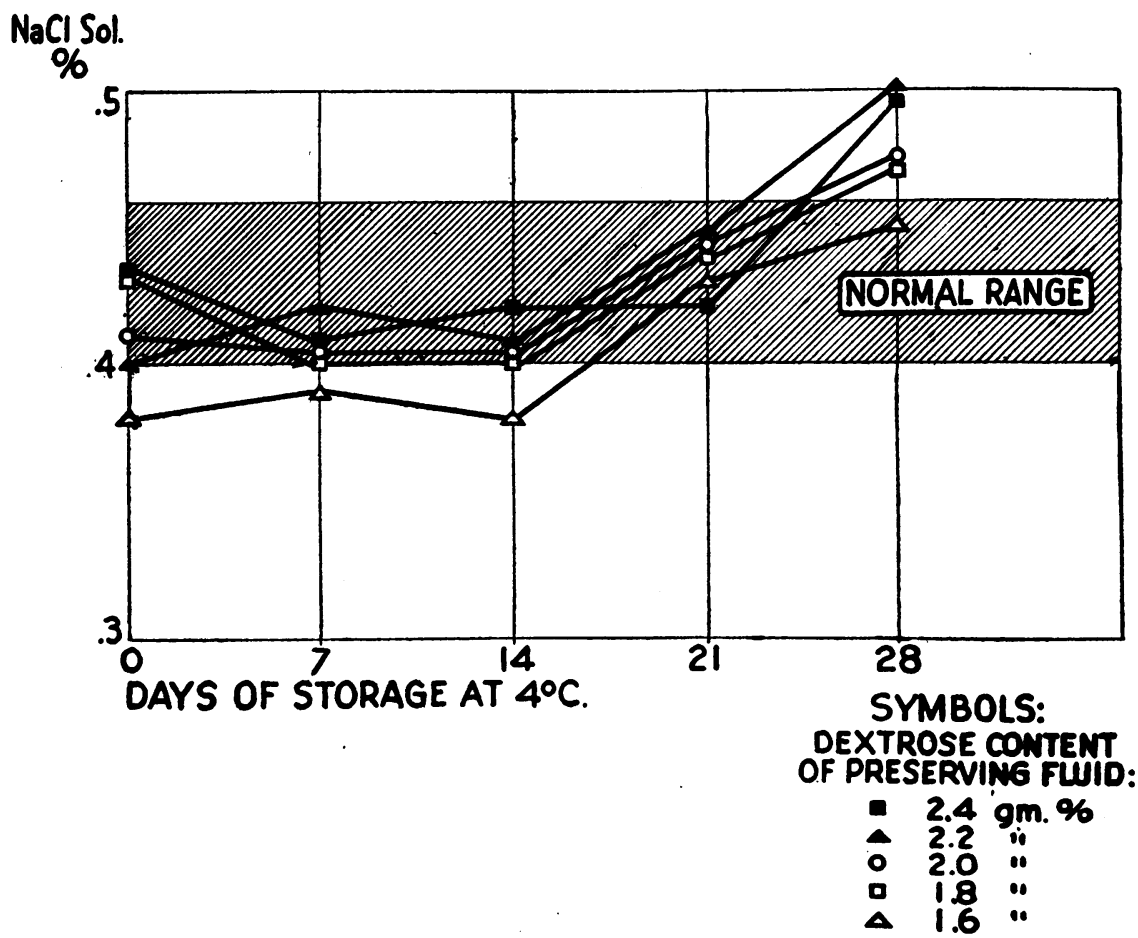

Fig. 2. Effect of Dextrose Concentration on the Osmotic Resistance of Erythrocytes (50 Pbr Cent Hemolysis Plotted) 


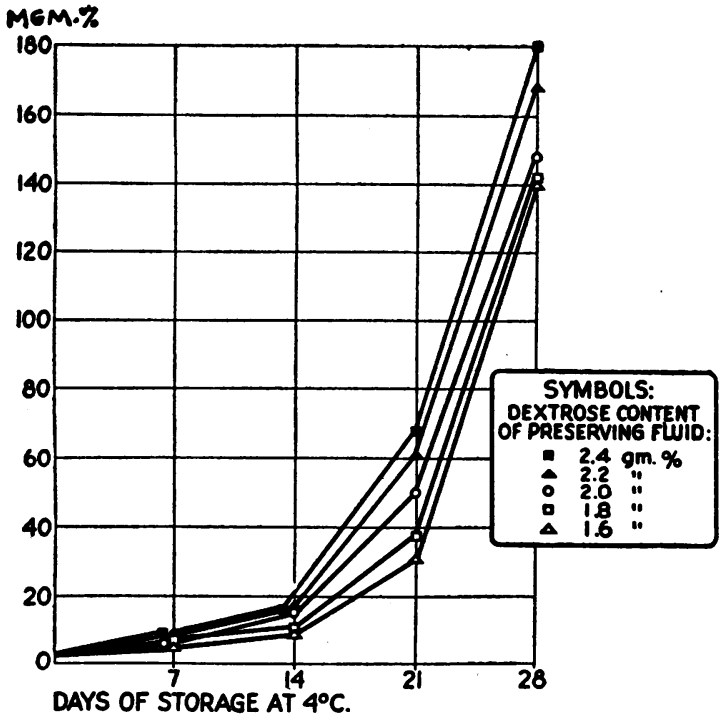

Fig. 3. Effect of Dextrose Concentration on Hemoglobin in the Supernatant Plasma

week. The higher dextrose concentration showed a greater hemolysis (see Figure 3 ).
From these studies in vitro it was concluded that the amount of dextrose could be profitably reduced. Accordingly the following formula was adopted (February 1945) for further clinical trials :

$$
\text { B.M.H.-A.C.D. No. } 3
$$

Sodium citrate (trisodium, dihydric) 1.6 grams Citric acid (monohydric) $0.56 \mathrm{gram}$ Dextrose (anhydrous) 1.5 grams Water $75 \mathrm{ml}$.

Seventy-five $\mathrm{ml}$. of this solution are placed in each collecting bottle and steam sterilized at $120^{\circ}$ C. for 20 minutes. The $\mathrm{pH}$ of this solution is 4.8 and the $\mathrm{pH}$ of the resulting plasma varied from 7.05 to 7.45 (see Table I).

This formula was compared with the B.M.H.A.C.D. No. 2 in a series of studies in vitro. It was noted that with the B.M. No. 3 the mean corpuscular volume remained within the normal range for at least 28 days, whereas with the B.M. No. 2 the tendency was to swelling beyond normal much sooner.

TABLE I

B.M.H. No. 3

A.C.D. plasma (75 $\mathrm{ml}$.)

\begin{tabular}{|c|c|c|c|c|c|c|c|c|c|c|c|c|c|c|c|}
\hline \multirow{2}{*}{$\begin{array}{l}\text { No. of } \\
\text { bleed- } \\
\text { ings }\end{array}$} & \multirow{2}{*}{$\begin{array}{l}\text { Pool } \\
\text { No. }\end{array}$} & \multirow{2}{*}{$\begin{array}{c}\text { Days } \\
\text { preserv } \\
\text { blood } \\
\text { average }\end{array}$} & \multirow{2}{*}{\begin{tabular}{|c} 
Blood \\
average
\end{tabular}} & \multirow{2}{*}{ Hb. } & \multirow{2}{*}{$\begin{array}{l}\text { Pro- } \\
\text { throm. } \\
\text { normal }\end{array}$} & \multirow{2}{*}{$\begin{array}{l}\text { Pro- } \\
\text { tein }\end{array}$} & \multirow{2}{*}{ pH } & \multirow{2}{*}{$\begin{array}{c}\text { Tur- } \\
\text { bidity } \\
\text { filter66 }\end{array}$} & \multicolumn{7}{|c|}{ Complement titration } \\
\hline & & & & & & & & & $\frac{1}{2}$ & $t$ & $t$ & it & $\frac{1}{32}$ & को & d \\
\hline 12 & $339 \mathrm{~A}$ & 4.3 & $\begin{array}{c}m l . \\
454\end{array}$ & $\begin{array}{c}\underset{\text { per cent }}{\operatorname{mgm}} \\
2.6\end{array}$ & $\begin{array}{c}\text { per cent } \\
78\end{array}$ & $\begin{array}{c}\text { grams } \\
\text { per cent } \\
6.1\end{array}$ & 7.41 & 107 & - & - & - & \pm & + & ++ & + \\
\hline 13 & 339B & 8.8 & 396 & 3.8 & 80 & 6.4 & 7.20 & 72 & - & - & - & - & $+{ }_{+}^{+}$ & $\begin{array}{l}++ \\
++\end{array}$ & \\
\hline 12 & 339D & 8.2 & 430 & 2.9 & 80 & 6.2 & 7.30 & 72 & - & - & - & - & $\begin{array}{c}++ \\
+\end{array}$ & & \\
\hline 13 & $341 \mathrm{~A}$ & 8 & 396 & 3.4 & 78 & 6.1 & 7.20 & 76 & - & - & - & - & + & $\begin{array}{c}+ \\
+\end{array}$ & \\
\hline 11 & 341B & 9.7 & 436 & 3.7 & 72 & 6.2 & 7.05 & 66 & - & - & - & - & + & ++ & \\
\hline 13 & $341 \mathrm{D}$ & 8.5 & 458 & 3.0 & 77 & 6.2 & 7.20 & 69 & - & - & - & - & + & $+{ }_{+}^{+}$ & \\
\hline 11 & $345 A$ & 8 & 414 & 3.8 & 77 & 6.3 & 7.40 & 68 & - & - & - & - & \pm & ++ & \\
\hline 11 & 345B & 10 & 436 & 2.9 & 78 & 6.4 & 7.40 & 63 & - & - & - & - & \pm & $\begin{array}{c}++ \\
+\end{array}$ & 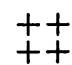 \\
\hline 11 & $345 \mathrm{D}$ & 3.2 & 395 & 3.9 & 70 & 6.2 & 7.45 & 69 & - & - & - & - & + & ++ & \\
\hline 12 & 346 & 8 & 475 & 4.0 & 74 & 6.1 & 7.30 & 67 & - & - & - & - & + & + & +- \\
\hline
\end{tabular}


A comparison of results of the studies of the osmotic resistance with the 2 solutions shows (see Figure 4) that the blood preserved in the B.M. No. 3 with lower dextrose content, remained within the normal limits for at least 35 days whereas, with the B.M. No. 2, abnormal resistance developed by the eighteenth day.

\section{IN VIVO STUDIES}

\section{Radioactive iron}

Radioactive iron studies on the survival of transfused erythrocytes after varying lengths of storage at $4^{\circ}$ C. in B.M.-A.C.D. No. 3 have been reported elsewhere (2). The study showed optimal preservation up to at least 22 days, the survival of the erythrocytes being 84 per cent, a result better than that obtained with any other preserving fluid tested.

\section{Hyperbilirubinemia}

Determinations of the recipient's serum bilirubin. level were carried out immediately before and 3 hours after completion of the transfusions. Figure 5 shows the result of such studies in 48 transfusions. The volume of transfusions was 450 to 500 ml. of whole blood (not including the preserving fluid).

While the data are as yet insufficient to allow a definite conclusion to be reached, there appeared to be no increase in the rate of hyperbilirubinemia during the first 21 days of storage.

\section{Clinical observations}

From 2/7/45 up to date, 5,010 specimens of blood have been collected in the Bryn Mawr A.C.D. No. 3. Studies of 1,215 whole blood transfusions were made and the reaction rate as well as the expected clinical results have been found to be optimal. No difficulties were encountered in the filtration of blood preserved up to 22 days. A complete description of a type of filter suitable for whole blood is given elsewhere (6). Proper filtration is obtained with finely woven nylon, stainless steel cloth (100 mesh) or multiple layers of more loosely woven gauze. When employing ordinary 40-mesh gauze, it should be used in 4 thicknesses.

To allow rapid filtration of blood, the filtering surface with any of the above mentioned materials should be 30 to 38 sq. $\mathrm{cm}$.

It is essential to maintain the blood in constant slow rotating motion while it is being collected (7) and to mix the blood thoroughly before administration by gently rotating the bottle held at various angles for at least 3 minutes.

An objection was raised concerning the possibility that with lowered dextrose content the glycolytic action of the erythrocytes would deplete the dextrose before the estimated period of maximal

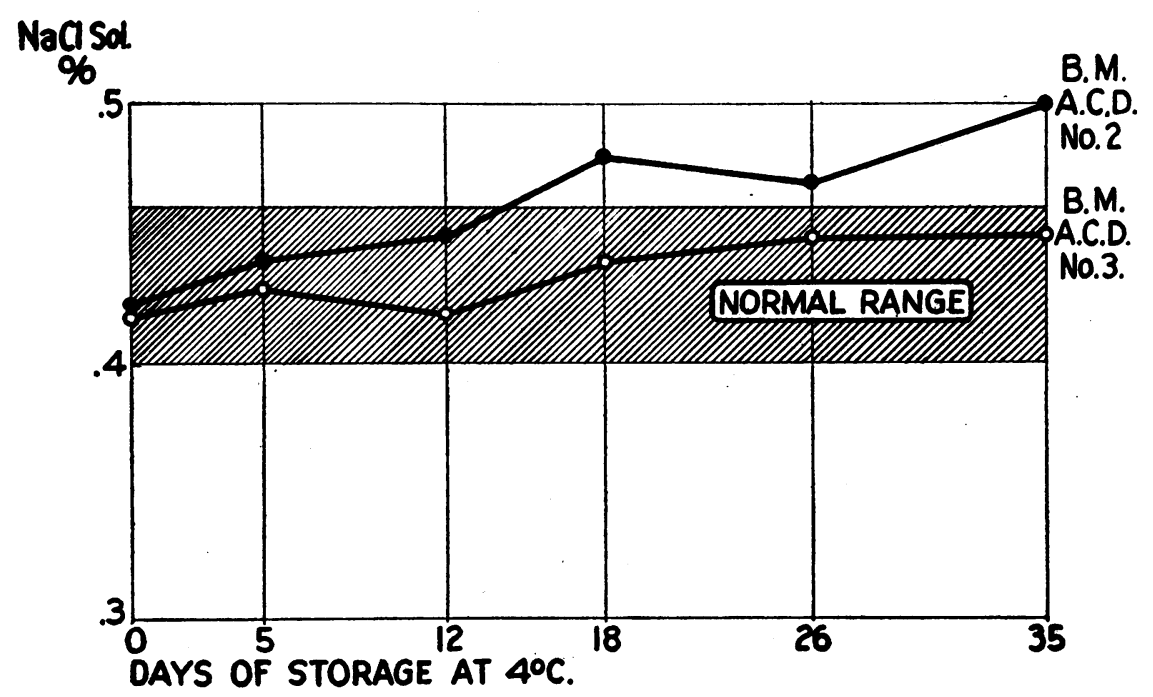

Fig. 4. Osmotic Resistance of Erythrocytes Stored in Bryn Mawr A.C.D. No. 2 and No. 3 


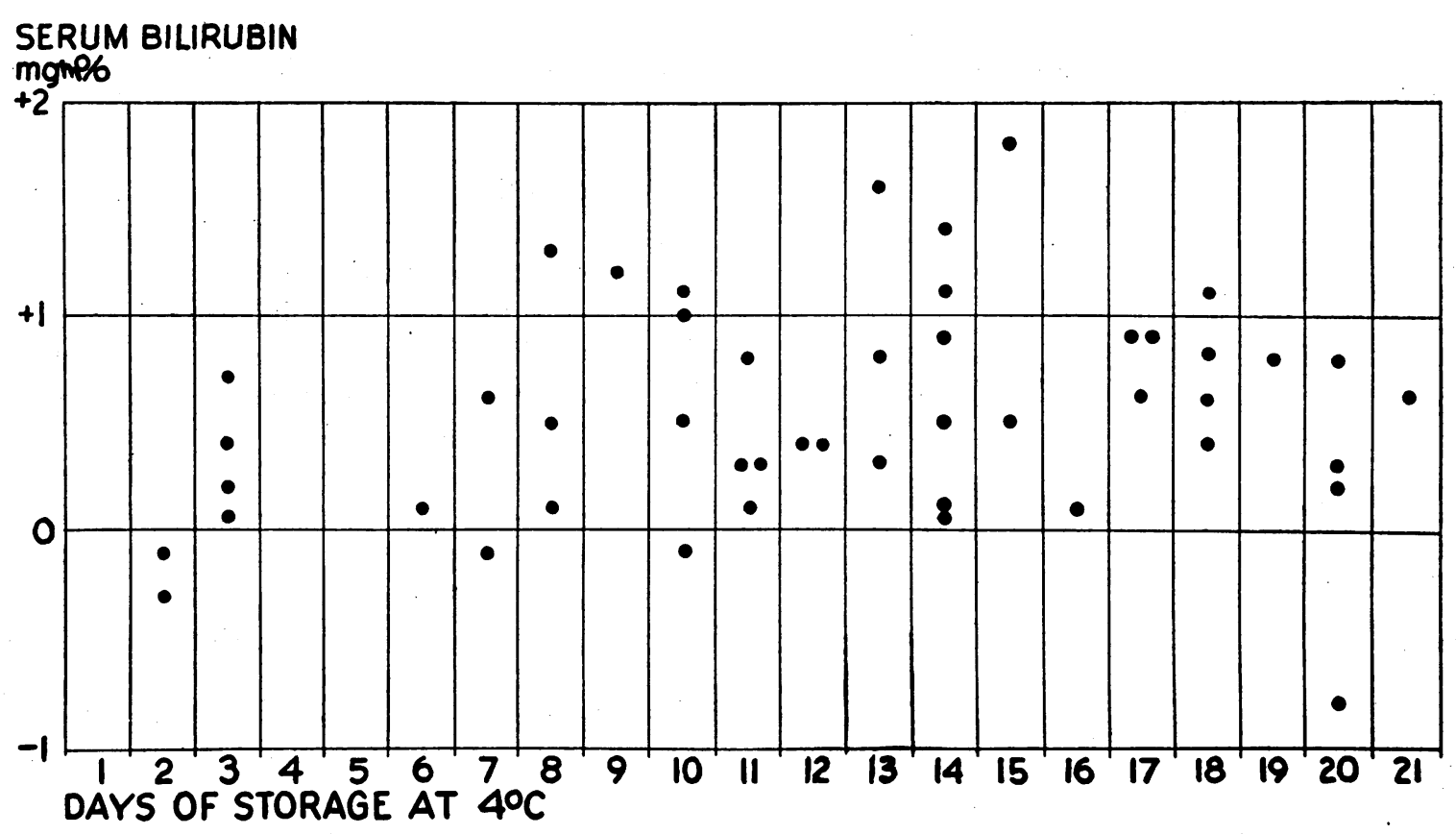

Fig. 5. Variations in Serum Bilirubin Concentration Immediately Before and 3 Hours After Transfusion of,Blood Stored in A.C.D. B.M. No. 3

preservation of 4 weeks. Repeated studies have shown that such is not the case. For the determination of the dextrose content of whole blood and plasma, samples of blood were taken as described previously. A protein-free filtrate of whole blood and of plasma was prepared by the Folin-Wu technic and the dextrose content was determined by the Benedict method. The dextrose content of the red cells was calculated by differential.

Dextrose appears to be present in optimal concentration in both plasma and erythrocytes for at least 28 days (normal content of dextrose in plasma $95 \mathrm{mgm}$. per cent and in erythrocytes 66 mgm. [see Figure 6]).

These studies were repeated in a series of random specimens of blood obtained from the blood bank. The data contained in Figure 7 were obtained from determinations done on routine blood bank specimens, varying in volume from 450 to 500 ml. of whole blood. These were collected in the B.M.-A.C.D. No. 3, chilled and preserved undisturbed at $4^{\circ} \mathrm{C}$. The dextrose determinations were done on an aliquot of well mixed blood obtained at the time of delivery of blood for administration to patients. The determinations were carried out by the Benedict method.
Figure 7 shows that for preservation up to 21 days at least $190 \mathrm{mgm}$. or more of dextrose are present.

\section{A.C.D. PLASMA}

The general composition of 10 pools of plasma obtained from blood preserved in B.M.-A.C.D. No. 2 were studied. When the findings were compared with similar ones obtained from the study of lots of plasma similarly prepared from plain citrated blood, it was found that the B.M.-A.C.D. No. 2 plasma had a lower hemoglobin content, a lower prothrombin content, a lower complement content, a lower protein content, a lower $\mathrm{pH}$, and a lower turbidity. It is important to keep in mind that the A.C.D. blood was stored before separation of plasma for a period of time comparable to that of the plain citrated blood but that the dilution was somewhat greater. It was also found that the fibrinogen in the A.C.D. No. 2 plasma was definitely more unstable than in the ordinary citrated plasma. Flocculation of fibrinogen occurred more readily in plasma kept in the liquid state or thawed from the frozen state. A very considerable improvement in the quality of plasma was obtained by using the B.M.-A.C.D. 


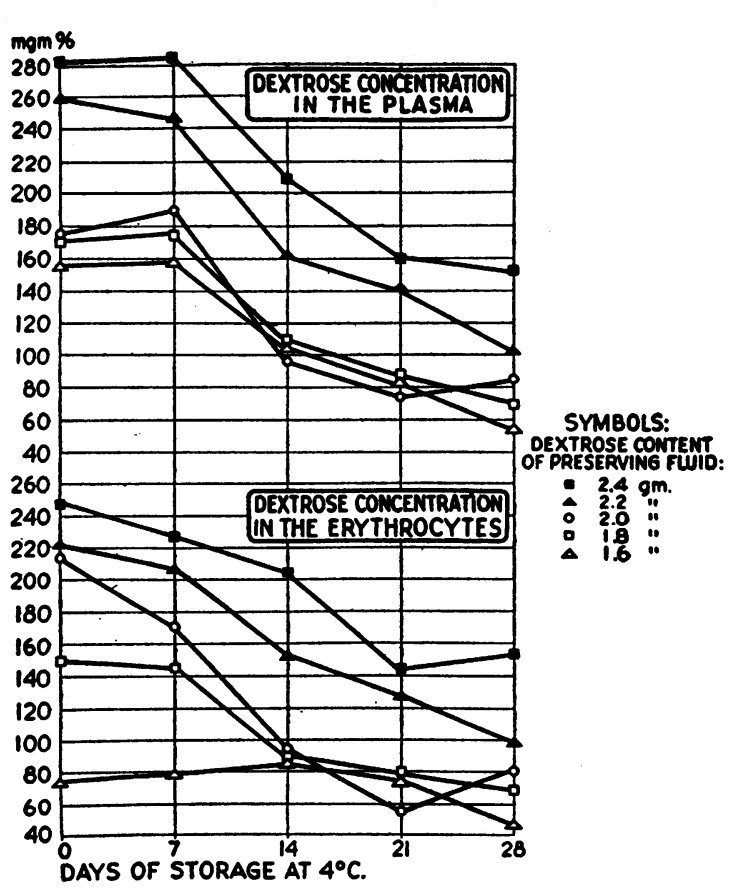

FIG. 6

No. 3 solution for the preparation of plasma. The general composition of 10 pools of such plasma is given in Table $\mathrm{I}$.

When these findings were compared with those from lots of plasma similarly prepared from the B.M.-A.C.D. No. 2 solution (see Table II) it

TABLE II

Comparison of plasma obtained with A.C.D. solutions

\begin{tabular}{l|c|c}
\hline \hline & B.M.H. & B.M.H. \\
& No.2 & No.3 \\
A.C.D. & A.C.D \\
sol. & sol. \\
& $100 \mathrm{ml}$. & $75 \mathrm{ml}$. \\
\hline Total no. of bleedings & 110 & 119 \\
${\text { Average time of preservation at } 4^{\circ} \text { C., days }}$ & 8.8 & 8.7 \\
Average volume of bleedings, $m l$. & 465 & 429 \\
Hemoglobin, mgm. per cent $^{\text {Prothrombin, per cent of normal }}$ & 5 & 3.4 \\
Protein, grams per cent (actual) & 61.5 & 76.4 \\
Protein, grams per cent (calculated) & 5.2 & 6.2 \\
Turbidity filter 66 & 5.1 & 5.7 \\
pH & 74.9 & 72.9 \\
Complement titration & 6.84 & 7.29 \\
& Comparable \\
\hline
\end{tabular}

was found that the plasma obtained with the B.M. -A.C.D No 3 solution had lower free hemoglobin, substantially higher protein and prothrombin content, and comparable turbidity and complement titration although the average size of the bleeding was $36 \mathrm{ml}$. (8 per cent) less.
From Table II it is noted that the actual protein concentration is somewhat higher than one calculated from simple dilution factors. This is probably due to the fact that water enters the red cells whereas the protein does not, so that there is some concentration of proteins in the plasma. In other words the increase in concentration of the plasma protein is due to the increased hematocrit of the red cells. The $\mathrm{pH}$ of the plasma from the B.M.-A.C.D. No. 3 averages 7.29 instead of 6.85 of the previous solution. This change was responsible for the improved prothrombin preservation. It was also noted that when the plasma obtained with the use of the B.M.-A.C.D. No. 3 was frozen and thawed, according to the proper procedure outlined elsewhere, the fibrinogen was fully as stable as that obtained from the plain citrated blood. This optimal stability of fibrinogen is conditional on proper mixing of the blood and preserving fluid during the collection. The necessity of proper mixing of blood with the preservative solution cannot be sufficiently emphasized. This mixing must be done by a gentle continuous ro-

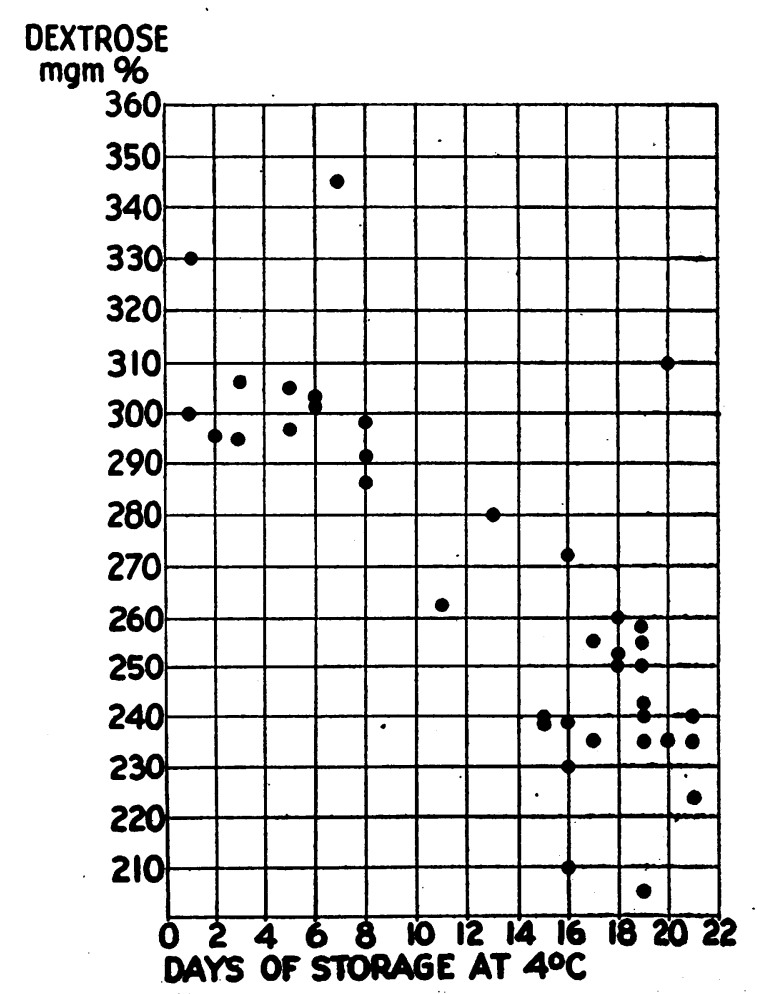

Fig. 7. Dextrose Concentration in Whole Blood Stored at $4^{\circ}$ C. in A.C.D. Solution (B.M. No. 3) 
tating motion. This is best accomplished by the use of a mechanical rotator, which does away with the unavoidable irregularities of the hand mixing and with the necessity of having a person in attendance for each patient. The rotators provided by the A. H. Thomas Co. of Philadelphia have been found excellent when fitted with a suitable heavy wooden bottle holder. Extensive studies have shown that the plasma obtained with the B.M. -A.C.D. No. 3 solution can be preserved in the frozen state or dried from the frozen state with results in all ways comparable with those obtained when a plain citrated plasma is used. It is to be noted here that when plasma prepared from whole blood preserved in a solution containing a higher glucose content is dried, the period of drying is lengthened because of the necessity of maintaining the plasma at a lower temperature while the water is being sublimated. When regenerating plasma prepared from A.C.D. blood, the use of a .1 per cent citric acid solution exerts the same beneficial effect in the preservation of prothrombin which has been noted for the plain citrated plasma (8).

\section{CONCLUSIONS}

An acid citrate-dextrose solution is proposed which has given good results for preservation of whole blood and yields a good stable plasma. This A.C.D. solution has a smaller volume and a lower dextrose concentration than solutions previously used. This solution has proved entirely satisfactory in practical use in over 5,000 blood collections.

\section{BIBLIOGRAPHY}

1. Loutit, J. F., Mollison, P. L., and Young, I. M., Citric acid-sodium citrate-glucose mixtures for blood storage; report to Medical Research Council from Southwest London Blood Supply Depot. Quart. J. Exper. Physiol., 1943, 32, 183.

2. Strumia, M. M., Blake, A. D., and Wicks, W. A., The preservation of whole blood. J. Clin. Invest., 1947, $26,667$.

3. Bulletin of the Subcommittee on Blood Substitutes, January 19, 1945 meeting, Washington, D. C.

4. See technical note at end of paper.

5. Parpart, A. K., Lorenz, P. B., Parpart, E. R., Gregg, J. R., and Chase, A. M., The osmotic resistance (fragility) of human red cells. J. Clin. Invest., 1947, 26, 636.

6. Strumia, M.M., Filter-drip unit for dispensing blood and plasma. Am. J. Clin. Path., Tech. Sect., 1944, 8,75 .

7. Strumia, M.M., McGraw, J. J., and Reichel, J., The preparation and preservation of human plasma. I. Collection of blood and separation of plasma. Am. J. Clin. Path., 1941, 11, 175.

8. Strumia, M. M., Preservation of prothrombin in dried plasma. J. A. M. A., 1942, 119, 710.

\title{
TECHNICAL NOTE
}

\section{DETERMINATION OF HEMOGLOBIN IN PLASMA (VISUAL COLORIMETRY)}

\author{
By W. G. KARR AND F. W. CHORNOCK
}

SOLUTIONS :

Acetic acid-10 per cent:

Pipette $10 \mathrm{ml}$. glacial acetic acid into a $100 \mathrm{ml}$. volumetric flask and dilute to mark.

Benzidine dihydrochloride:

Dissolve $140 \mathrm{mgm}$. of benzidine dihydrochloride in about $200 \mathrm{ml}$. of water with warming. Cool, add $3.3 \mathrm{ml}$. of 10 per cent acetic acid and dilute to 500 $\mathrm{ml}$. in a volumetric flask. Keep in a brown bottle in the refrigerator. (The acidity of this reagent is correct only for use with plasma as directed below.)

Hydrogen peroxide-1 per cent:

Dilute $0.5 \mathrm{ml}$. of Merck 30 per cent Superoxol to 15 $\mathrm{ml}$. in a graduate. Prepare this solution just before use.

\section{Artificial standard:}

Ferric ammonium sulfate-1 per cent.

Potassium ferrocyanide -1 per cent.

Gum ghatti $\quad-1$ per cent.

The iron and the ferrocyanide solutions are prepared accurately by careful weighing and dilution in a volumetric flask. Select clean, purple crystals of ferric ammonium sulfate. The gum ghatti is made approximately by suspending 1.5 grams on a wire or cloth gauze in $100 \mathrm{ml}$. of cold water and allowing it to dissolve overnight. If necessary, filter through cheesecloth to remove particulate matter.

In a liter volumetric flask, pipette exactly $13.0 \mathrm{ml}$. of the 1 per cent potassium ferrocyanide. Dilute to about $900 \mathrm{ml}$. Add $10 \mathrm{ml}$. of 1 per cent gum ghatti. 
Add $20 \mathrm{ml}$. of the 1 per cent ferric ammonium sulfate. Dilute to mark. Mix. Keep in ice box.

Color is equivalent to $25 \mathrm{mgm}$. Hb per $100 \mathrm{ml}$. when the color is developed as in Method described below.

\section{Serial standards:}

Prepare $250 \mathrm{ml}$. of each of the following dilute standards by diluting the artificial standard with water as indicated.

$\begin{array}{ccc}\text { Water } & \text { Standard } & \begin{array}{c}\text { Hb. equiv. (C) } \\ \text { mgm. per } 100 \text { ml. }\end{array} \\ 0 & 250 & 25 \\ 50 & 200 & 20 \\ 100 & 150 & 15 \\ 150 & 100 & 10 \\ 200 & 50 & 5\end{array}$

Mix and place in $250 \mathrm{ml}$. bottles. Keep in ice box.

METHOD :

Dilute $1 \mathrm{ml}$. of plasma to $10 \mathrm{ml}$. with water. Measure $4 \mathrm{ml}$. of the dilute plasma into a test tube. Add
$15 \mathrm{ml}$. of the benzidine dihydrochloride reagent. Add $1 \mathrm{ml}$. of the 1 per cent hydrogen peroxide and mix. Immerse in an ice bath for 35 minutes. At the end of this time select the artificial standard which is nearest the color of the unknown plasma. Pour $20 \mathrm{ml}$. into a test tube and add $0.4 \mathrm{ml}$. of the original undiluted plasma. Compare in the colorimeter.

If the blue color developed is appreciably greater than the $25 \mathrm{mgm}$. standard, the determination should be repeated using $4 \mathrm{ml}$. of a dilution of plasma greater than 1 to 10 . Make appropriate change in the calculation.

\section{CALCULATION :}

$X=\mathrm{mgm} . \mathrm{Hb}$. per $100 \mathrm{ml}$. plasma.

$S=$ reading of standard on the right.

$U=$ setting of the unknown on the left.

$C=$ equivalent $\mathrm{Hb}$. concentration of the artificial standard selected for reading.

$$
X=\frac{S}{U} \times C . \quad \text { Set } U \text { at } 10 . \quad X=\frac{S \times C}{10} \text {. }
$$

Blank: $4 \mathrm{ml}$. diluted plasma plus $15 \mathrm{ml}$. benzidine reagent plus $1 \mathrm{ml}$. water in icebath with unknowns. 